\title{
Effect of Coconut Shell Powder as Filler on the Mechanical Properties of Coir-polyester Composites
}

\author{
Md. Tangimul Islam ${ }^{1}$, Subrata Chandra Das ${ }^{1,2, *}$, Joykrisna Saha ${ }^{1}$, Debasree Paul ${ }^{1,3}$, \\ M. Tauhidul Islam ${ }^{1,3}$, Mahbubur Rahman ${ }^{1}$, Mubarak Ahmad Khan ${ }^{4}$ \\ ${ }^{1}$ Department of Textile Engineering, Mawlana Bhashani Science and Technology University, Bangladesh \\ ${ }^{2}$ Pabna Textile Engineering College, Pabna-6600, Department of Textiles, Ministry of Textiles and Jute, Bangladesh \\ ${ }^{3}$ Department of Textile Engineering, Khwaja Yunus Ali University, Sirajgonj, Bangladesh \\ ${ }^{4}$ Atomic Energy Research Establishment, Bangladesh Atomic Energy Commission, Dhaka, Bangladesh
}

Copyright $\bigcirc 2017$ by authors, all rights reserved. Authors agree that this article remains permanently open access under the terms of the Creative Commons Attribution License 4.0 International License

\begin{abstract}
Coir mat was used as reinforcement, polyester resin was used as matrix and coconut shell powder (CSP) was used as filler material which was employed as 10, 20,30, 40, 50, 60 and $100 \%$ by weight in the composites. Coir mat/polyester resin composites were made by hand lay-up technique. Mechanical properties such as tensile strength (TS), bending strength (BS), tensile modulus (TM), bending modulus (BM), elongation at break and impact strength (IS) were also investigated. The maximum increase of TS, BS, TM, BM and IS were found to be $44.44,128.00,17.96,112.09$ and $62.50 \%$ respectively for $30 \%$ filler content on the composites. It was revealed that the strength properties of the composites were increased with the increase in filler content up to $30 \%$ by weight, however, further increase in filler content the value decreased. Gamma radiation of 100, 250 and $300 \mathrm{krad}$ doses were applied on 30, 40 and $60 \%$ filler content composites. Gamma radiation dose of $250 \mathrm{krad}$ showed better result than that of other doses. IS of the composites improved 48.08, 26.67 and $17.50 \%$ for 30,40 and $60 \%$ filler content respectively at $250 \mathrm{krad}$, where $30 \%$ filler content composites displayed the highest improvement. Degradation tests of the composites for up to 50 days were performed in a soil medium. It was revealed that BS decreased for all the composites.
\end{abstract}

Keywords Coir Mat, CSP, Polyester Resin, Filler, Gamma Radiation

\section{Introduction}

Natural fiber polymer composites have gained huge attention from the last decade due to the environmental concern. Generally, natural fibers are biodegradable and renewable, so it has no harmful effect on the environment. Besides, it is available, cheap, low weight, low abrasion, high toughness, acceptable specific mechanical properties, durable and ease of processability [1-7]. That is why scientists are so much attracted to make the fiber useful in our daily life and try to make it an alternative solution for synthetic fibers. Several investigations have been carried out to assess the potential of natural fibers as reinforcement in the polymers. The results have shown that natural fibers present potential to be used as reinforcement for plastics, but generally they do not attain the full mechanical performance levels of glass fibers reinforced plastics [8-16].

Among all the natural fibers, coir is a very common in South Asian subcontinent and widely used in various applications such as brushes, floor mats, heavy cord, coarse nets etc. The seed hair fiber coir is obtained from the outer shell or husk of coconut fruit Cocus nucifera from the tropical plant of Arecaceae (Palmae) family. This coconut shell is inedible part of coconut fruit which is solid lignocellulosic agro waste. It is an eco-friendly cheap fiber which can be even less expensive than sisal and jute [17]. Coconut shell is $15-20 \%$ of coconut; it includes $36-43 \%$ cellulose, and related substance containing $41-45 \%$ hemicelluloses, $0.15-0.25 \%$ lignin, and $3-4 \%$ pectin. The cell length is about $0.8 \mathrm{~mm}$, spiral angle $41-45^{\circ}$ holding tensile strength of 131-175 $\mathrm{MPa}$, elongation at break $15-40 \%$ and tensile modulus of 4-6 GPa [18-21] that is hydrophilic glucan polymer along with linear chain of $1,4-\beta$ bonded anhydroglucose unit, which contains alcoholic hydroxyl groups [22]. Coconut fiber is the toughest fiber (21.5 MPa) amongst natural fibers and able to taking strain 4-6 times more than that of other fibers [23, 24]. The chemical components and the mechanical properties of some natural fibers are summarized in Table 1 $[21,25,26]$. 
Table 1. Chemical composition and structural parameters of some natural fibers

\begin{tabular}{|c|c|c|c|c|c|}
\hline \multirow{2}{*}{ Chemical composition $(\%)$} & \multicolumn{5}{|c|}{ Types of fiber } \\
\hline & Coir & Jute & Flax & Sisal & Cotton \\
\hline Cellulose & $36-43$ & $61-71.5$ & 71 & $67-78$ & 82.7 \\
\hline Hemicelluloses & $41-45$ & $13.6-20.4$ & $18.6-20.6$ & $10-14.2$ & 5.7 \\
\hline Lignin & $0.15-0.25$ & $12-13$ & 2.2 & $8-11$ & - \\
\hline Pectin & $3-4$ & 0.2 & 2.2 & 10 & - \\
\hline Wax & - & 0.5 & 1.7 & 2 & 0.6 \\
\hline Cellulose length (mm) & - & 0.8 & 2.3 & 20 & 2.2 \\
\hline Spiral angle $\left({ }^{\circ}\right)$ & $41-45$ & 8 & 10 & 20 & - \\
\hline Moisture content (\%) & 8 & 12.6 & 10 & 11 & - \\
\hline Water soluble (\%) & Some & 1.1 & 3.9 & 1.2 & - \\
\hline Tensile strength (MPa) & $131-175$ & $393-773$ & $354-1100$ & $468-640$ & $287-800$ \\
\hline Elongation at break (\%) & $15-40$ & $1.16-1.5$ & $2.7-3.2$ & $3-7$ & $7-8$ \\
\hline Young's Modulus (GPa) & $4-6$ & $13-26.5$ & 27.6 & $5.5-12.6$ & $5.5-12.6$ \\
\hline
\end{tabular}

For low cost roofing materials, Cook et al. [27] studied the applications of coconut fiber reinforced cement composites and various parameters such as fiber lengths, fiber volumes, casting pressure for low cost roofing materials. The best results found for composites which contained $3.75 \mathrm{~cm}$ length, $7.5 \%$ volume fraction and under 1.67 MPa pressure and it was cheaper than that of locally available roofing stuffs. The effect of fillers such as fly ash, $\mathrm{Al}_{2} \mathrm{O}_{3}, \mathrm{Mg}(\mathrm{OH})_{2}$ and hematite powder on the mechanical properties of E-glass/epoxy composites were investigated by Devendra et al. [28]. Composites filled by $10 \%$ volume $\mathrm{Mg}(\mathrm{OH})_{2}$ exhibited maximum ultimate tensile strength and hardness and fly ash filled composites found superior impact strength. Harish et al. reported the average values of tensile strength, bending strength and impact strength of 17.86 MPa, 31.08 MPa and $11.49 \mathrm{~kJ} / \mathrm{m}^{2}$ respectively for randomly oriented coir fibers/epoxy composites [29]. The tensile properties of coir-polyester composites were analyzed by Junior et al. [30] and the mechanical features of coir fiber reinforced cement sand mortar were investigated by Slate [31]. The variation of bending strenght with the mass fraction of coir fibers and molding pressure were studied by Monteiro et al. [32]. To increase the mechanical properties and minimize the water absorbency, grafting of monomers onto cellulose based natural fibers by application of radiation can be an effective technique [33]. Sathyanarayana et al. [34] carried a study of fibers from various structural parts of the coconut palm tree have been experimented for properties such as size, density, electrical resistivity, ultimate tensile strength, initial modulus and elongation\%. Sandhyarani et al. [35] continued the above methodology and obtained remarkable enhancement on the mechanical characteristics of coir-epoxy composites. Yao et al. [36] studied the use of coir fiber to get good impact toughness of composites. Research is ongoing to replace synthetic fibers with lignocellulosic fibers as reinforcing fillers [37-41].
Nowadays, synthetic polymers are incorporated with various reinforcing fillers to enhance the mechanical properties and obtain the characteristics demanded in actual application [42-44].

The present study deals with the fabrication and mechanical analysis of coir mat reinforced polyester composites. The major purpose of this work was to study the effect of filler materials on the physico-mechanical properties of the composites. After that, to study the effect of filler content, soil degradation test and gamma radiation were performed.

\section{Experimental}

\subsection{Materials}

Coir yarn was collected from local market at Sirajgonj and Coir shell powder (CSP) from local market at Barisal, Bangladesh. Unsaturated polyester resin and Methyl Ethyl Ketone Peroxide (MEKP) were collected from Polynt Composite Malaysia.

\subsection{Methods}

\subsubsection{Fabrication of the Composites}

Fabrication of composite was done by conventional method called hand lay-up method. A mold of dimension $210 \times 210 \times 40 \mathrm{~mm}^{3}$ was used. Polyester resin with its corresponding hardener (MEKP) in a predetermined ratio was thoroughly mixed. Mold releasing silicon spray was applied to mold releasing sheet and then the chopped fiber, mixed with the resin was gently poured on the sheet which was placed inside the mold. The purpose of releasing agent was to facilitate easy removal of the composite from the mold after curing. The mixture was allowed to set inside the mold for a period of 4 hours under a pressure of $20 \mathrm{~kg}$ 
over the cast. After removing the weight, the composite was kept in room temperature for 72 hours. Then the specimen was cut into appropriate dimension for mechanical testing. In this fabrication procedure, seven classes of composites were made with different compositions of CSP in the composites such as $0,10,20$, $30,40,60,100 \%$ filler content by weight. Composites with $0 \%$ filler content indicates only coir-polyester composites and filler is not used here. On the other hand, 100\% filler content composite indicates CSP filler-polyester composites and coir fiber is not used in this case.

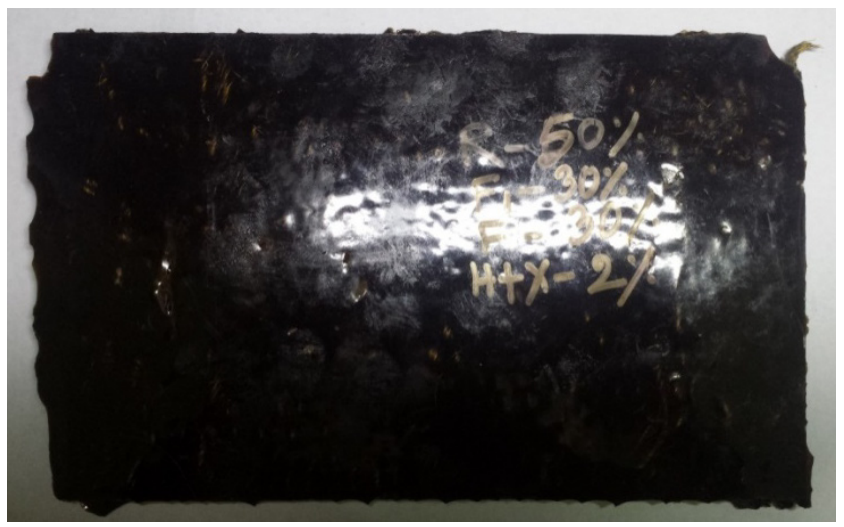

Figure 1. Coir mat reinforced polyester composite with $30 \%$ CSP filler

\subsubsection{Irradiation of the Composites}

The composite samples were irradiated using a Co-60 gamma source $(25 \mathrm{kci})$ of the Atomic Energy Research Establishment, Savar, Dhaka, for different doses (100, 250 and $500 \mathrm{krad}$ ).

\subsubsection{Mechanical Testing of the Composites}

\subsubsection{Tensile Test}

Tensile tests were conducted according to ASTM Designation: D638-03 using a Universal Testing Machine (model: H50KS-0404, Hounsfield Series S, UK) with a cross-head speed of $10 \mathrm{~mm} / \mathrm{min}$ at a span distance of $50 \mathrm{~mm}$. The dimensions of the test specimen were $120 \mathrm{~mm} \times 15 \mathrm{~mm}$.

\subsubsection{Flexural Test}

Static flexural tests were carried out according to ISO 14125 method using the same testing machine mentioned above with a cross-head speed of $60 \mathrm{~mm} / \mathrm{sec}$ at a span distance of $25 \mathrm{~mm}$. The dimensions of the test specimen were $60 \mathrm{~mm} \times 15 \mathrm{~mm}$.

\subsubsection{Impact Test}

The impact tests were conducted on unnotched mode composite specimens according to ASTM D 6110-97 using a Universal Impact Tester (HUNG TA INSTRUMENT CO. LTD, Taiwan), hammer mass of $2.63 \mathrm{~kg}$, gravity distance of $30.68 \mathrm{~mm}$ and lift angle of $150^{\circ}$.

\subsubsection{Water Absorption}

Composite samples were immersed in the static water beaker at room temperature for different time periods up to 72 hours. Prior to immersion in water, the specimens were dried in an oven at $105^{\circ} \mathrm{C}$, cooled in a desiccators using silica gel and weighed. After certain periods of time, samples were taken out from the bath and wiped using tissue paper, then weighed. Water uptake was determined by the subtraction from final weight to initial weight.

\subsubsection{Degradation in Soil}

Composites samples were buried in soil (having at least $25 \%$ moisture) for 50 days. After the composites were withdrawn carefully and washed with distilled water. The excess water from the sample surface was removed by tissue paper. These samples kept at room temperature for 24 hours and then measured the tensile strength properties.

\section{Result and Discussion}

\subsection{Mechanical Properties}

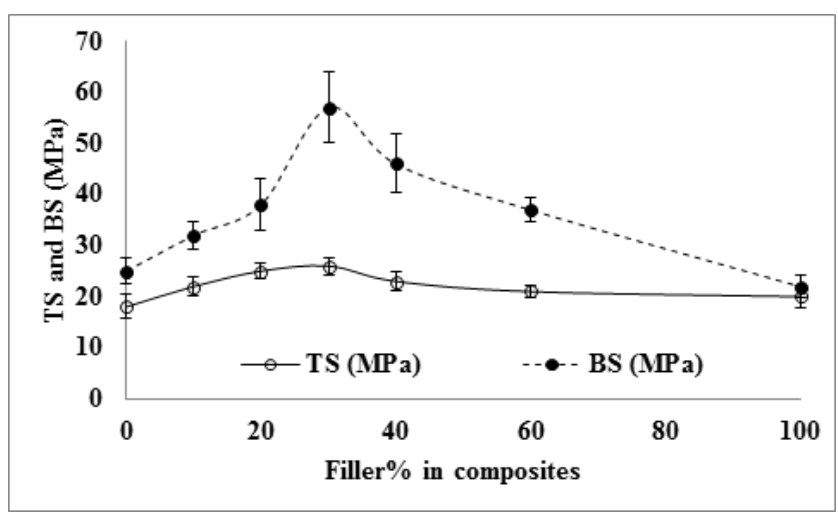

Figure 2. Effect of filler\% on tensile strength (TS) and bending strength (BS) of coir-polyester composites

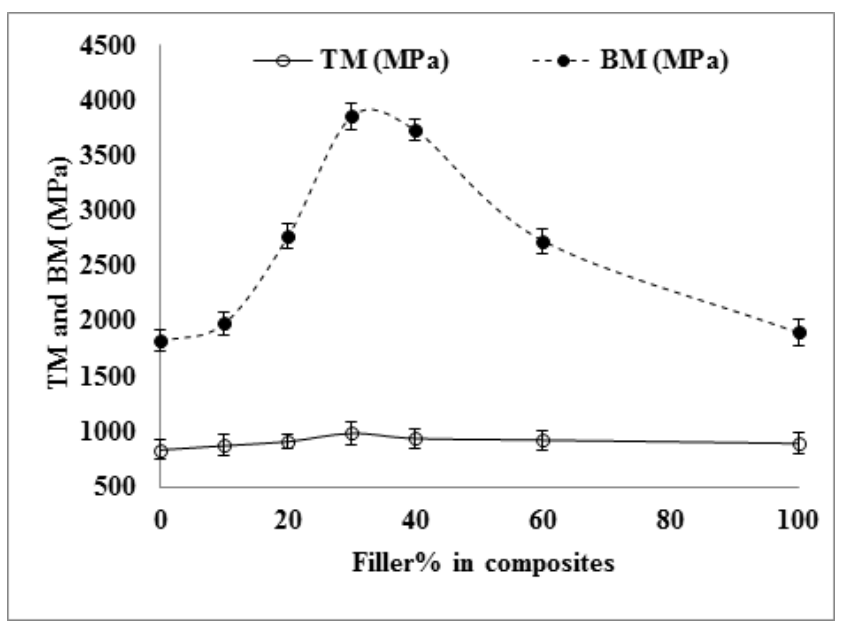

Figure 3. Effect of filler\% on tensile modulus (TM) and bending modulus (BM) of coir-polyester composites 


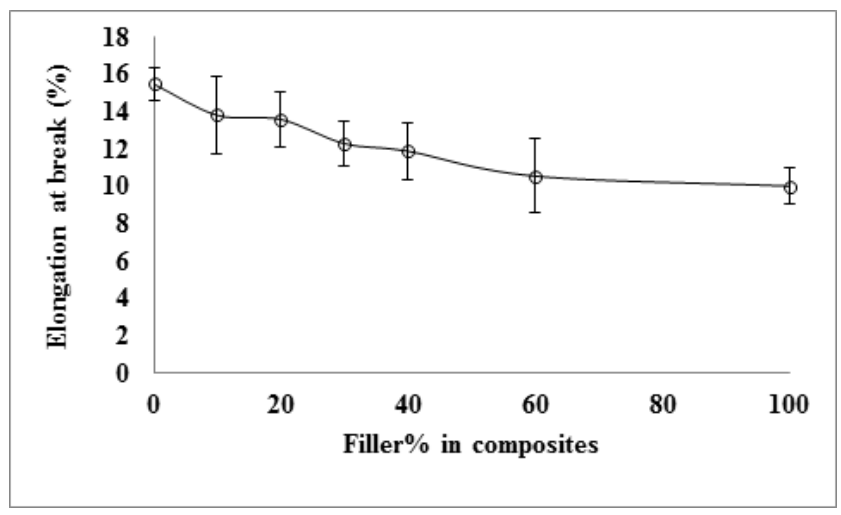

Figure 4. Effect of filler\% on elongation at break of coir-polyester composites

Figure 2 shows the effect of filler content (wt $\%$ ) on TS and BS of the coir mat reinforced polyester composites. It is observed that for $0,10,20,30,40,60,100 \%$ filler content the value of TS and BS found to be $18,22,25,26$, 23, 21, $20 \mathrm{MPa}$ and $25,32,38,57,46,37,22 \mathrm{MPa}$ respectively. The highest increase of TS and BS found be $44.44 \%$ and $128.00 \%$ respectively at $30 \%$ filler content composites than that of the unfilled one ( $0 \%$ filler), and then the TS and BS of the composites decrease with the addition of filler\% in the composites as shown in Figure 2. Leha et al. also studied the effect of filler from 10 to $40 \%$ and revealed that $25 \%$ filler content composite exhibited the highest TS and BS, then with the addition of filler\% it displayed a decreasing trend of mechanical properties up to $40 \%$ filler [45]. This decline might be attributed to two reasons: one possibility is that due to the presence of pores at the interface between the filler particles and the matrix, the interfacial adhesion may be too weak to transfer the tensile stress; the other is that the corner points of the irregular shaped particulates result in stress concentration in the matrix body. As the filler content increases, instead of dispersion the gathering of fillers take place and the resin cannot wet the fibers due to non-entrance of resin in-between the two adjacent fibers. The reduction in BS of the composites with filler content is probably caused by an incompatibility of the fillers and the polyester matrix, leading to poor interfacial bonding. The lower values of bending properties may also be attributed to fiber to fiber interaction, voids and dispersion problems. However, it also depends on other factors such as the size, shape and type of the filler material.

TM of the fabricated composites are found to be 835 , $873,910,985,939,924$ and $894 \mathrm{MPa}$ for the addition of 0 , $10,20,30,40,60$ and $100 \%$ filler content respectively. The increase of TM are found to be $4.55,8.98,17.96,12.46$, 10.66 and $7.07 \%$ for the addition of 10, 20,30, 40, 60 and $100 \%$ filler content respectively as shown in Fig. 3. On the other hand, the BM are 1820, 1980, 2270, 3860, 3730, 2730 and $1900 \mathrm{MPa}$ for $0,10,20,30,40,60$ and $100 \%$ filler content respectively. The increases of $\mathrm{BM}$ are found to be $8.79,52.20,112.09,104.95,50$ and $4.40 \%$ for 10,20 ,
$30,40,60$ and $100 \%$ filler addition respectively. It is evident that TM and $\mathrm{BM}$ increases with the increased of filler materials up to $30 \%$ (by weight) and then it decreases as shown in Fig. 3. Normally, the fibers in the composite restrain the deformation of the matrix polymer, reducing the tensile strain $[46,47]$. So even if the strength decreases with filler addition, the TM of the composite is expected to increase as has been observed in the present investigation. But further increases in filler content up to $100 \mathrm{wt} \%$, the $\mathrm{TM}$ of the composites are found to be decreasing. The reasons for the lower bending properties at higher filler content are probably due to the weak fiber-to-fiber interaction, void and poor dispersion of fiber in the matrix. Generally, CSP filler offer greater resistance to crack initiation and propagation in the composite. Due to which there is an increase bending strength of composites with coir shell powder filler as compared to without filler.

The elongation at break (\%) of the composites for the addition of filler content of $0,10,20,30,40,60$ and $100 \%$ are found to be 15.51, 13.84, 13.61, 12.32, 11.91, 10.58, $10.04 \%$ respectively as shown in Fig.4. The elongation at break of the composites decreases with increasing filler content because the addition of filler reduce the mobility and increase the brittleness of the composites. Increasing the amount of filler decreases the amount of fiber available for elongation (Figure 4). The reasons for the lower elongation properties at higher filler content are filler fill-up the void portion of the composites. Generally, CSP filler offer greater resistance to crack initiation and propagation in the composites. Due to which there is a decrease of elongation\% of composites with CSP filler as compared to without filler.

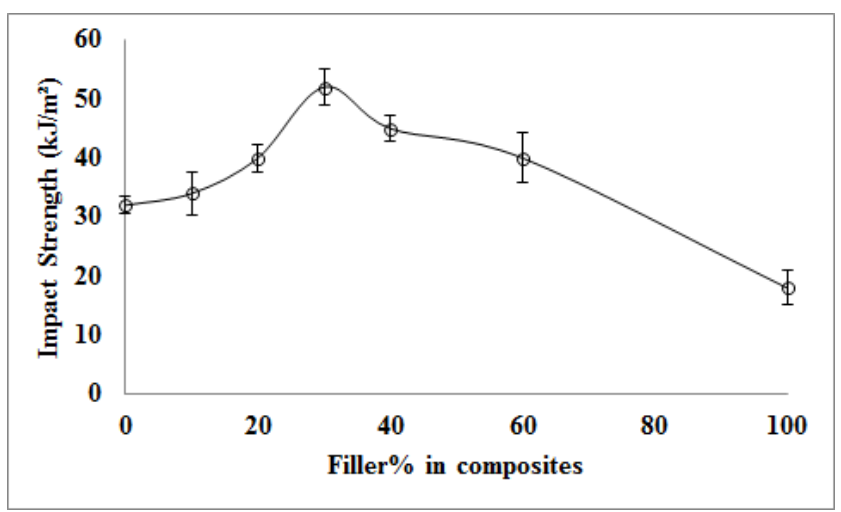

Figure 5. Effect of filler\% on the impact strength (IS) of coir-polyester composites

The IS of a material is its capacity to absorb and dissipate energies under impact or shock loading. IS of the composites are found to be $32,34,40,52,45,40$ and $18 \mathrm{~kJ} / \mathrm{m}^{2}$ for the filler content of $0,10,20,30,40,60$ and $100 \%$ in the composites respectively. From the Figure 5, it is observed that the IS increases with the increase in filler content up to $30 \mathrm{wt} . \%$ (62.50\% improvement than unfilled one) and further it exhibits a declining trend upon filler addition. It has been reported that higher filler content 
increases the probability of fiber agglomeration and it stress concentration requiring less energy for crack propagation. The maximum IS of the composite increase with filler content up to $30 \mathrm{wt} . \%$. Similar trend were found by Leha et al. [45] where $20 \%$ filler content composite showed the best result $(0.082 \mathrm{~J})$, then with the increase of filler\% in composites, the IS declines up to $0.056 \mathrm{~J}$ for $40 \%$ filler content composite. The reasons are that the filler is capable of absorbing energy and compression pressure which removes the voids contents in the composites because of appreciative mix-up filler and matrix.

\subsection{Effect of Gamma Radiation}

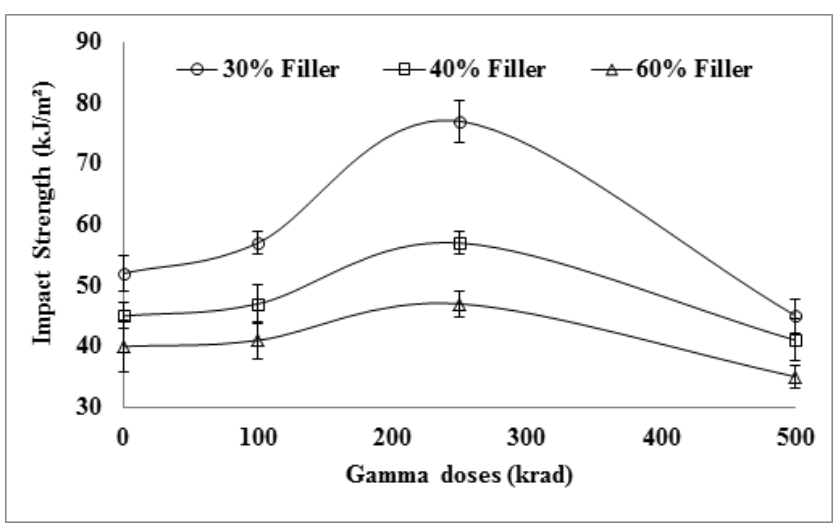

Figure 7. Effect of gamma radiation on impact strength (IS) of the filler content coir-polyester composites

Three types of composites such as 30,40 and $60 \%$ filler content coir mat polyester composites have been treated by gamma irradiation at 100,250 and $500 \mathrm{krad}$ doses and IS found to be $57,77,45 \mathrm{~kJ} / \mathrm{m}^{2}, 47,57,41 \mathrm{~kJ} / \mathrm{m}^{2}$ and 41,47 , $35 \mathrm{~kJ} / \mathrm{m}^{2}$ for the composites of $30 \%, 40 \%$ and $60 \%$ filler content respectively as shown in Fig. 7. It is revealed that at $250 \mathrm{krad}$ dose of gamma irradiation, all composites show the maximum improvement of IS which are 48.08, 26.67 and $17.50 \%$ for 30,40 and $60 \%$ filler content composites respectively, where $30 \%$ filler content composites displays the highest improvement ( $48.08 \%$ increase of IS). IS of the composite is influenced by the interfacial bond strength, the matrix and the fiber. Gamma irradiation may affect the polymeric structure of the coir fiber and polyester matrix, which may produce active sites that can contribute to better fiber and matrix bonding. At low radiation dose, bond scission and cross-linking occurred, but at higher dose scission was preferred. Gamma irradiation may also remove moisture from the composite, which in turn contributed to better fiber matrix adhesion. This may be the reason behind the increased mechanical properties of the composites.

\subsection{Soil Degradation of the Composites}

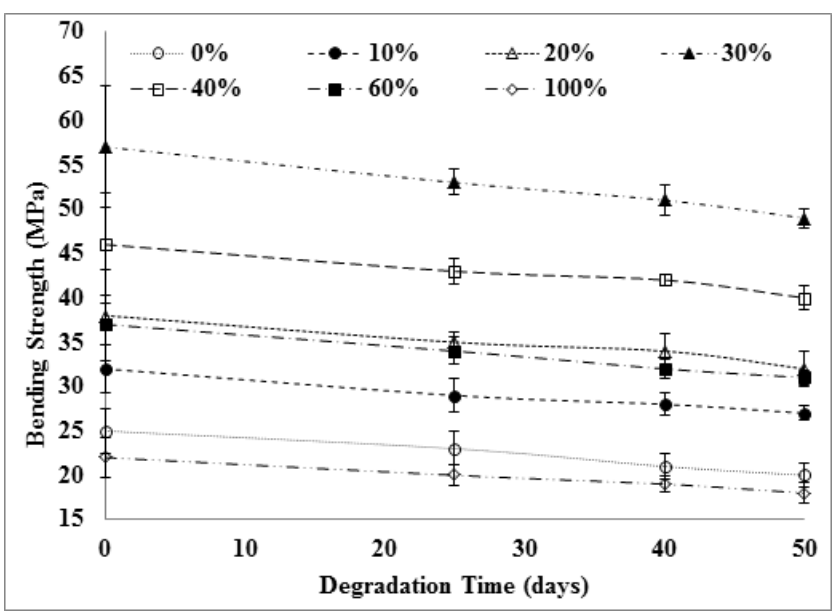

Figure 6. Effect of soil degradation on bending strength (BS) of the filler content coir-polyester composites

After buried in soil for 25 days of the test specimens, the $\mathrm{BS}$ are $23,29,35,53,43,34$ and $20 \mathrm{MPa}$ for $0,10,20,30$, 40,60 and $100 \%$ filler content composites respectively as shown in Fig. 6. The loss of BS has been observed 6.6, 8.86, $8.69,7.03,7.67,9.77$ and $7.49 \%$ for $0,10,20,30,40,60$ and $100 \%$ filler content composites respectively after 25 days of soil degradation. After buried in soil for 40 days, the BS are $21,28,34,51,42,32,19 \mathrm{MPa}$ and loss of BS found to be $13.74,18.17,17.88,15.92,16.35,19.02$, $16.81 \%$ for the composites of $0,10,20,30,40,60$ and $100 \%$ filler content respectively. Finally, after 50 days of soil degradation, the BS are 20, 27, 32, 49, 40,31, $18 \mathrm{MPa}$ and loss of BS are found 13.74, 18.17, 17.88, 15.92, 16.35, $19.02,16.81 \%$ for the composites containing $0,10,20,30$, 40, 60 and $100 \%$ filler respectively. Maximum loss of BS is observed $19.02 \%$ for $60 \%$ filler and minimum loss of BS observed $13.74 \%$ for $0 \%$ filler content specimens. It is revealed that increasing degradation time reduces the possibility of strength loss of the composites and composite without filler exhibits less BS loss where $60 \%$ filler content sample shows highest loss of BS. Moreover, composites containing filler materials display loss of BS drastically. Coir is a natural biodegradable fiber and, because it is cellulose-based, it absorbs water within a couple of minutes, indicating its strong hydrophilic character. Cellulose has a strong tendency to degrade when buried in soil [48, 49]. During soil-degradation tests, water penetrates from the cutting edges of the composites in coir-based samples and degradation of cellulose occurs in coir, microbial degradation may also take place; as a result, the mechanical properties of the composites decrease significantly. 


\section{Conclusions}

Coir polyester composites successfully fabricated with the incorporation of CSP as filler materials. It was revealed that by the incorporation of fillers the mechanical properties were improved than that of the composite without fillers and the maximum improvement were found for $30 \%$ filler content. The addition of filler $\%$ on composites increased the mechanical properties up to $30 \%$ filler but after that it showed a decreasing trend. Gamma radiation of $250 \mathrm{krad}$ exhibited better improvement of impact properties of the composites but further higher doses of radiation decreased the properties. The soil degradation experiment displayed the loss of BS for all the composites where coir mat/polyester composite (without fillers) exhibited minimum loss of BS than that of filler content composites. Finally, it can be concluded that filler\% and radiation has significant influence on the mechanical properties of coir polyester composites. The proper optimization of these processing parameters can be a better or viable solution of this composite for our domestic applications.

\section{Acknowledgements}

The authors have been acknowledged to the Institute of Radiation and Polymer Technology (IRPT), Atomic Energy Research Establishment (AERE), Bangladesh Atomic Energy Commission, Savar, Dhaka for using their laboratory to complete this work.

\section{REFERENCES}

[1] Saha, J., Das, S. C., Rahman, M., Siddiquee, M. A. B., and Khan, M. A., 2016, Influence of polyester resin treatment on jute fabrics for geotextile applications, Journal of Textile Science and Technology, 2(4), 67-80. Doi: 10.4236/jtst.2016.24009

[2] Mohanty, A. K., Misra, M., and Hinrichsen, G., 2000, Biofibers, biodegradable polymer and biocomposites: an overview, Macromolecular Materials and Engineering, 276, $1-24$.

[3] Joseph, P. V., Joseph, K., and Thomas, S., 2002, Short sisal fiber reinforced polypropylene composites: the role of interface modification on ultimate properties, Composite Interfaces, 9(2), 171-205.

[4] Cantero, G., Arbelaiz, A., Llano-Ponte, R., and Mondragon, I., 2003, Effects of fiber treatment on wettability and mechanical behavior of flax/polypropylene composites, Composites Science and Technology, 63, 1247-1254.

[5] Lee, S. M., Cho, D., Park, W. H., Lee, S. G., Han, S. O. and Drzal, L. T., 2005, Novel Silk/Poly(butylene succinate) Biocomposites: The Effect of Short Fiber Content on Their Mechanical and Thermal properties. Composites Science and Technology, 65, 647-657.

http://dx.doi.org/10.1016/j.compscitech.2004.09.023

[6] Das, S. C., Islam, M. T., Khan, M. A., Mamun, M. A. A. Mittro, B. K., Saha, J. and Paul, D., 2017, Fabrication and mechanical characterization of PALF plain fabric reinforced polyester biocomposites, Paper ID: 76, pp. 55, International Conference on Computer, Communication, Chemical, Materials and Electronic Engineering $\mathrm{IC}^{4} \mathrm{ME}^{2}-2017$, University of Rajshahi, Rajshahi, Bangladesh.

[7] Myrtha, K., Holia, O., Dawam, A. A. H., and Anung, S., 2008, Effect of oil palm empty fruit bunch fiber on the physical and mechanical properties of fiber glass reinforced polyester resin, Journal of Biological Sciences, 8, 101- 106. Doi: http://dx.doi.org/10.3923/jbs.2008.101.106

[8] Das, S. C., Paul, D., Siddiquee, M. A. B., Islam, J. M. M., and Khan, M. A., 2016, Experimental investigation and analysis of mechanical behavior of jute fabric reinforced polyester composites, ICMIEE-PI-160-167, International Conference on Mechanical, Industrial and Energy Engineering, Khulna, Bangladesh.

[9] Mulinari, D. R, Voorwald, H. J. C, Cioffi, M. O. H, Da Silva, M. L. C. P., and Luz, S. M., 2009, Preparation and properties of HDPE/sugarcane bagasse cellulose composites obtained for thermokinetic mixer, Carbohydrate Polymer, 75, 317-320.

[10] Das, S. C. and Nizam, M. E. H., 2014, Applications of fiber reinforced polymer composites (FRP) in civil engineering, International Journal of Advanced Structures and Geotechnical Engineering, 3(3), 299-309.

[11] Das, S. C., Paul, D., Islam, J. M. M., and Khan, M. A., 2016, Effect of gamma radiation on the mechanical properties of PET felt reinforced polyester composites, Paper ID: ICMIEE-PI-160337, International Conference on Mechanical, Industrial \& Energy Engineering 2016, Khulna, Bangladesh

[12] Khan, R. A., Haque, M. E., Khan, M. A., Zaman, H. U., Mohamad, K. J. F., and Ahmad, A., 2010, Studies on the relative degradation and interfacial properties between jute/polypropylene and jute/natural rubber composites, Journal of Thermoplastics Composite Materials, 25(5), 665-681.

[13] Khan, J. A., Khan, M. A., Islam, R., and Gafur, A., 2010, Mechanical, thermal and interfacial properties of jute fabric-reinforced polypropylene composites: effect of potassium dichromate, Materials Sciences and Applications, 1, 350-357. Doi: 10.4236/msa.2010.16051.

[14] Zaman, H. U., Khan, M. A., Khan, R. A., Noor-A-Alam, M. Bhuian, Z. H., 2012, Studies of the physico-mechanical interfacial, and degradation properties of jute fabrics/melamine composites, International Journal of Polymeric Materials, 61(10), 748-758. Doi: 10.1080/00914037.2011.610045

[15] Das, S. C., Paul, D., Siddiquee, M. A. B., Saha, J., Khan, M. A., and Islam, J. M. M., 2017, Study on the mechanical properties of non-woven glass fiber reinforced polyester composites, Paper ID: 75, International Conference on Computer, Communication, Chemical, Materials and Electronic Engineering IC $\mathrm{ME}^{2}-2017$, University of Rajshahi, Rajshahi, Bangladesh. 
[16] Pickering, K. L., Efendy, M. G. A., and Le, T. M., 2016, A review of recent developments in natural fiber composites and their mechanical performance, Composites Part A: Applied Science and Manufacturing, 83, 98-112. Doi: http://dx.doi.org/10.1016/j.compositesa.2015.08.038

[17] Geethamma, V. G., Mathew, K. T., Lakshminarayanan, R. and Thomas, S., 1998, Composite of short coir fibers and natural rubber: effect of chemical modification, loading and orientation of fiber, Polymer, 39(6), 1483-1491.

[18] Daniel, Z., and Maria, H., 2000, Domestication of plants in the old world, 3rd ed. Oxford University Press, Oxfordshire.

[19] Duke, J. A., 1989, Handbook of nuts, CRC Press, London.

[20] Bledzki, A. K., Reihmane, and S., Gassan, J., 1996, Properties and modification methods for vegetable fibers for natural fiber composites, Journal of Applied Polymer Science, 59, 1329-1336.

[21] Varma, D. S., Varma, M., and Varma, I. K., 1984, Coir fibers, part 1: effect of physical and chemical treatment on properties, Textile Research Journal, 54(12), 821-832. Doi: https://doi.org/10.1177/004051758405401206

[22] Hua, L., Zadorecki, P. and Flodin, P., 1987, Cellulose fiber-polyester composites with reduced water sensitivity (1)-chemical treatment and mechanical properties, Polymer Composites, 8, 199-202. DOI: 10.1002/pc.750080308

[23] Munawar, S. S., Umemura, K., and Kawai, S., 2007, Characterization of the morphological, physical, and mechanical properties of seven non-wood plant fibre bundles, Journal of Wood Science, 53(2), 108-13. doi:10.1007/s10086-006-0836-x

[24] Satyanarayana, K. G., Sukumaran, K., Mukherjee, P. S., Pavithran, C., Pillai, S. G. K., 1990, Natural fibre-polymer composites, Cement and Concrete Composites, 12(2), 117 136. https://doi.org/10.1016/0958-9465(90)90049-4

[25] Bledzki, A. K., Reihmane, S. and Gassan, J., 1996, Properties and modification methods for vegetable fibers for natural fiber composites. Journal of Applied Polymer Science, 59, 1329-1336.

Doi:10.1002/(SICI)1097-4628(19960222)59:8<1329::AIDAPP17>3.0.CO;2-0

[26] Bledzki, A. K., and Gassan, J., 1999, Composites reinforced with cellulose based fibres, Progress in Polymer Science, 24(2), 221-274. Doi: https://doi.org/10.1016/S0079-6700(9 8)00018-5

[27] Cook, D. J., Pama, R. P., and Weerasingle, H. L. S. D., 1978, Coir fibre reinforced cement as a low cost roofing material, Building and Environment, 13(3), 193-198.

[28] Devendra, K., and Rangaswamy, T., 2013, Strength characterization of E-glass fiber reinforced epoxy composites with filler materials, Journal of Minerals and Materials Characterization and Engineering, 1, 353-357. Doi: http://dx.doi.org/10.4236/jmmce.2013.16054

[29] Harish, S., Michael, D. P., Bensely, A., Mohan Lal, D., and Rajadurai, A., 2009, Mechanical property evaluation of natural fiber coir composite, Materials Characterization, 60, 44-49. Doi: https://doi.org/10.1016/j.matchar.2008.07.001

[30] Santafe Jr., H. P. G., Lopes, F. P. D., Costa, L. L., and Monteiro, S. N., 2010, Mechanical properties of tensile tested coir fiber reinforced polyester composites, Revista Materia, 15(2), 113-118.

[31] Slate, F. O., 1976, Coconut fibers in concrete, Engineering Journal of Singapore, 3(1), 51-54.

[32] Monteiro, S. N., Terrones, L. A. H., and D'Almeida, J. R. M., 2008, Mechanical performance of coir fiber/polyester composites, Polymer Testing, 27(5), 591-595. Doi: https://doi.org/10.1016/j.polymertesting.2008.03.003

[33] Ali, K. M. I., Khan, M. A., Ali, M. A., 1997, Study on jute materials with urethane acrylate by UV curing, Radiation Physics and Chemistry, 49(3), 383-388.

[34] Satyanarayana, K. G., Pillai, C. K. S., Sukumaran, K., Pillai, S. G. K., Rohatgi, P. K., and Vijayan, K., 1982, Structure property studies of fibres from various parts of the coconut tree, Journal of Material Science, 17(8), 2453-2462. Doi:10.1007/BF00543759

[35] Biswas, S., Kindo, S., and Patnaik, A., 2011, Effect of fiber length on mechanical behavior of coir fiber reinforced epoxy composites, Fibers and Polymers, 12(1), 73-78. Doi:10.1007/s12221-011-0073-9

[36] Yao, J., Hu, Y. C., Lu, W., and Li, J., 2011, Mechanical performance of a new coir fiber laminated composites, Advanced Materials Research, 217-218, 852-855. Doi: 10.4028/www.scientific.net/AMR.217-218.852

[37] Thwe, M. M., and Liao, K., 2002, Effects of environmental ageing on the mechanical properties of bamboo-glass fiber reinforced polymer matrix hybrid composites, Composites Part A, 33, 43-52.

[38] Park, B. D., Wi, S. G., Lee, K. H., Singh, A. P., Yoon, T. H., and Kim, Y. S., 2003, Characterization of anatomical features and silica distribution in rice husk using microscopic and micro-analytical techniques, Biomass and Bioenergy, 25(3), 319-327. Doi:

https://doi.org/10.1016/S0961-9534(03)00014-X

[39] Yang, H. S., Kim, H. J., Son, J., Park, H. J., Lee, B. J., and Twang, T. S., 2004, Rice-husk flour filled polypropylene composites; mechanical and morphological studies, Composite Structures, 63(3-4), 305-312. Doi https://doi.org/10.1016/S0263-8223(03)00179-X

[40] Rana, A. K., Mandal, A., and Bandyopadhyay, S., 2003, Short jute fiber reinforced polypropylene composites: effect of compatibiliser, impact modifier and fiber loading, Composites Science and Technology, 63, 801-806. Doi: http://dx.doi.org/10.1016/S0266-3538(02)00267-1

[41] Singleton, A. C. N., Baillie, C. A., Beaumont, P. W. R., and Pejis, T., 2003, On the mechanical properties, deformation and fracture of a natural fibre/recycled polymer composite, Composites Part B: Engineering, 34(6), 519-526. (2003). Doi: https://doi.org/10.1016/S1359-8368(03)00042-8

[42] Paul, D., Das, S. C., Shauddin, S. M., and Khan, M. A., 2014, Improvement of physico-mechanical properties of polyethylene terephthalate felt-polypropylene composites: effect of gamma radiation, Paper ID: PM-III-B 10, International Conference on Physics for Energy and Environment organized by the Bangladesh Physical Society (BPS), Atomic Energy Centre, Dhaka, Bangladesh.

[43] Yang, H. S., Kim, H. J., Park, H. J., Lee, B. J., and Hwang, T. 
S., 2007, Effect of compatibilizing agents on rice-husk flour reinforced polypropylene composites, Composite Structures, 77(1), 45-55. Doi:

https://doi.org/10.1016/j.compstruct.2005.06.005

[44] Choi, N. W., Mori, I., and Ohama, Y., 2006, Development of rice husks-plastic composites for building materials, Waste Management, 26(2), 189-194. Doi:

https://doi.org/10.1016/j.wasman.2005.05.008

[45] Leha, A. R. N., and Nordin, N. A., 2014, Effect of filler compositions on the mechanical properties of bamboo filler polyester composites, Advanced Materials Research, 879, 90-95. Doi: 10.4028/www.scientific.net/AMR.879.90

[46] Fu, S. Y., and Lauke, B., 1998, Characterization of tensile behavior of hybrid short glass fiber/calcite particles/ABS composites, Composites Part A: Applied Science and Manufacturing, 29(5-6), 575-583.
[47] Thomason, J. L., Vlug, M. A., Schipper, G., and Krikor, H. G. L. T, 1996, Influence of fibre length and concentration on the properties of glass fibre reinforced polypropylene: Part 3. Strength and strain at failure, Composites Part A: Applied Science and Manufacturing, 27(11), 1075-1084.

[48] Hassan, M. M.; Islam, M. R.; Khan, M. A., 2003, Improvement of physico-mechanical properties of jute yarn by photografting with 3-(trimethoxysilyl)

propylmethacrylate, Journal of Adhesion Science and Technology, 2003, 17(5), 737-750. Doi:

http://dx.doi.org/10.1163/156856103321340840

[49] Zaman, H. U.; Khan, M. A.; Khan, R. A.; Beg, D. H., 2011 , A comparative study on the mechanical, degradation and interfacial properties of jute/LLDPE and jute/natural rubber composites, International Journal of Polymeric Materials, 60(5), 303-315. 